\title{
Ectodermal Dysplasia Presenting with Atrophic Rhinitis: Report of Two Cases and Review of Literature
}

\author{
${ }^{1}$ Sampurna Pati, ${ }^{2}$ Sudipta Pal, ${ }^{3}$ Somnath Saha, ${ }^{4}$ Surajit Biswas
}

\section{ABSTRACT}

Aim: To present two rare case of ectodermal dysplasia presenting with maggot infestation due to atrophic rhinitis.

Study design: Case report.

Setting: Tertiary care referral hospital.

Presentation: Two male child aged about 5 and 8 years presented in ENT emergency with history of maggot infestation of nose.

Result: Clinical examination was suggestive of ectodermal dysplasia. Intranasal examination was suggestive of atrophic rhinitis. Maggots were removed in conventional manner. Following conservative treatment, skin biopsy and nasal mucosal biopsy was taken which confirmed the diagnosis of ectodermal dysplasia.

Conclusion: Any ectodermal dysplasia patient should be suspected of having atrophic rhinitis and intranasal conservative therapy should be initiated at the earliest to prevent complication like maggots in nose.

Keywords: Atrophic rhinitis, Ectodermal dysplasia, Nasal myiasis.

How to cite this article: Pati S, Pal S, Saha S, Biswas S. Ectodermal Dysplasia Presenting with Atrophic Rhinitis: Report of Two Cases and Review of Literature. Clin Rhinol An Int J 2015;8(3):133-135.

\section{Source of support: Nil}

Conflict of interest: None

\section{INTRODUCTION}

Sir Charles Darwin has mentioned in his book 'The Variation of Animal and Plants under Domestication'

\footnotetext{
${ }^{1}$ Consultant, ${ }^{2}$ Assistant Professor, ${ }^{3,4}$ Professor

${ }^{1}$ Department of ENT, Nova Superspeciality Hospital, Kolkata West Bengal, India

${ }^{2}$ Department of ENT, Calcutta National Medical College, Kolkata West Bengal, India

${ }^{3}$ Department of ENT, NRS Medical College, Kolkata, West Bengal, India

${ }^{4}$ Department of Dermatology, RG Kar Medical College, Kolkata West Bengal, India
}

Corresponding Author: Sudipta Pal, Assistant Professor Department of ENT, Calcutta National Medical College, Kolkata West Bengal, India, Phone: 9051757391, e-mail: drsudiptapal@ gmail.com about an Indian family with defective dentition and inability to sweat properly in 1838. Although Thurnam published the first report of a patient with ectodermal dysplasia in $1848,{ }^{1}$ the term ectodermal dysplasia was not coined until 1929 by Weech. ${ }^{2}$ Ectodermal dysplasia comprises of a large group of 192 distinct inherited disorders which are clinically and genetically heterogenous with the common features of abnormal, absent or delayed embryonic development of one or more of the epidermal and mucosal appendages. Among them most common disorders are hypohidrotic or anhidrotic ectodermal dysplasia (Christ-variety) has an estimated prevalence of 1 per 100,000 birth. ${ }^{3}$ The clinical triad of this disorder consists of hypotrichosis, anodontia or hypodontia and hypohydrosis or anhydrosis.

\section{CASE REPORT}

An 8 years old boy attended ENT emergency with the complaint of living insects coming out of nose with fever and generalised weakness. Detailed history was taken from his mother who revealed that her son suffered from recurrent attacks of high fever and heat intolerance along with occasional epistaxis, anosmia and purulent discharge from nose. He had frontal bossing with sparse thin hair in scalp and eyebrow, saddle nose and only three conical teeth (Figs 1 and 2). His developmental milestones and IQ level were in normal range. Anterior rhinoscopy showed lots of crusting in nasal cavity with maggots in nasal cavity with atrophic turbinates. Thermoregulation was achieved after admission and maggots were removed. Skin biopsy was performed which revealed absence of eccrine sweat glands and biopsy from nasal mucosa showed absence of mucous glands (Figs 3 and 4). Thus the child was diagnosed to be suffering from the rare disorder of anhidrotic ectodermal dysplasia. He had no family history of similar disease and his male sibling was not affected.

The second similar case presented to our department with maggots in nose. This 5 years old boy came from a remote village with nasal myiasis and bilateral ear discharge. His body temperature was $103 \mathrm{~F}$ and he was in a very irritable state. After admission the maggots were removed and thermoregulation restored by repeated cold sponging. He had the same facies as the previous case but 


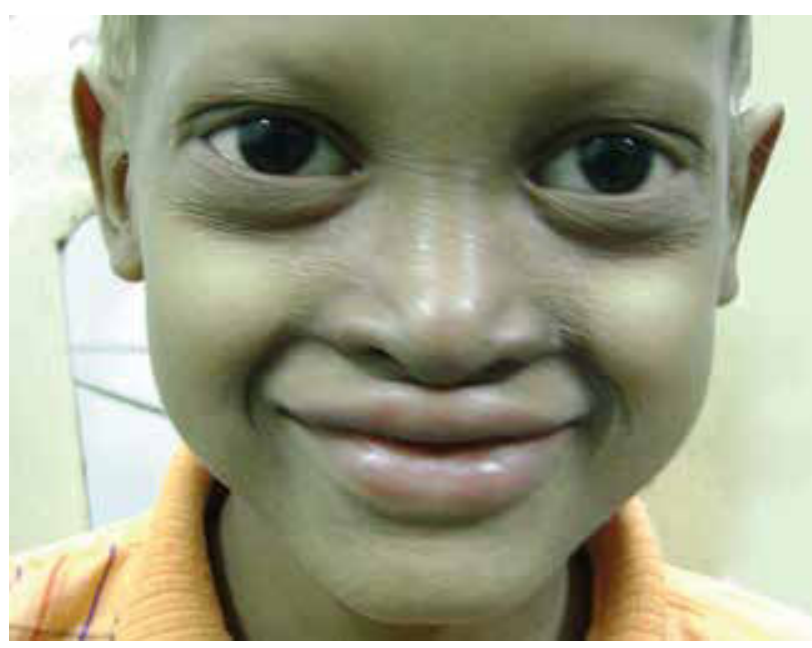

Fig. 1: Clinical photograph of the first patient

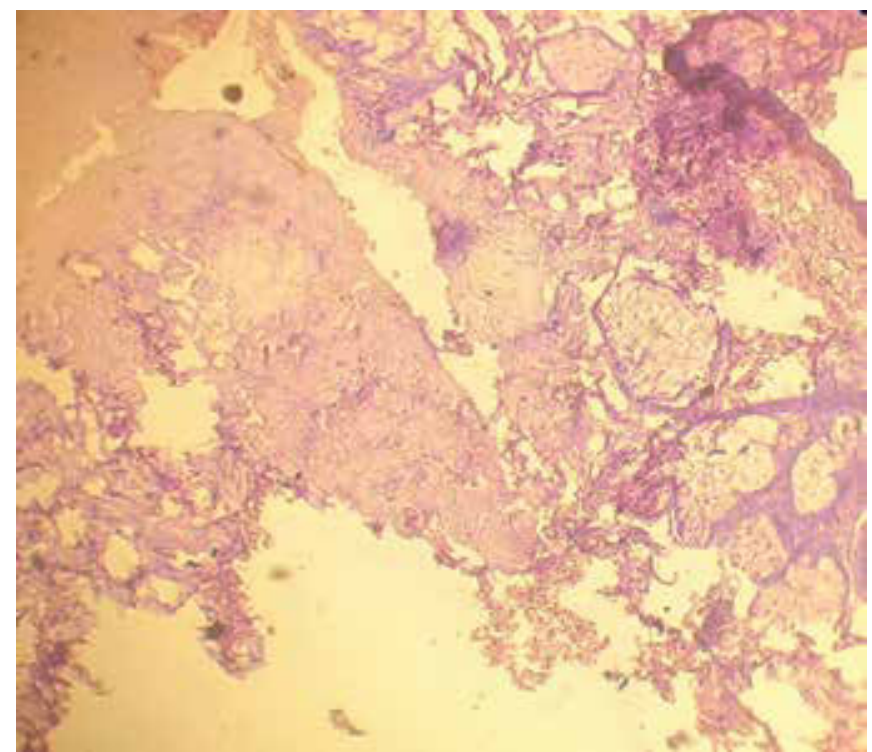

Fig. 3: Histopathological slide from skin biopsy showing absence of eccrine glands

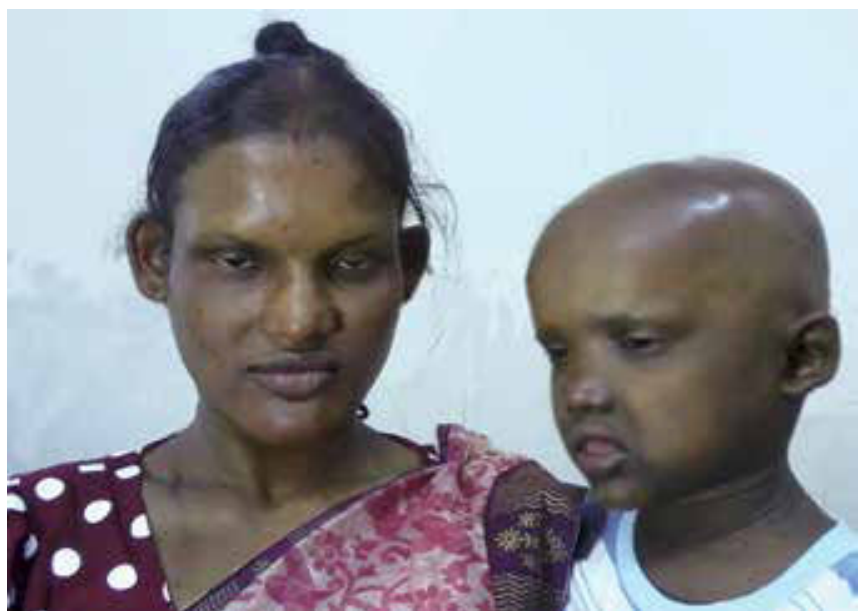

Fig. 5: Clinical photograph of the second patient with his mother

with complete alopecia and very dry skin. Interestingly his mother also had sparse thin hair, dry skin and inability to sweat properly (Fig. 5).

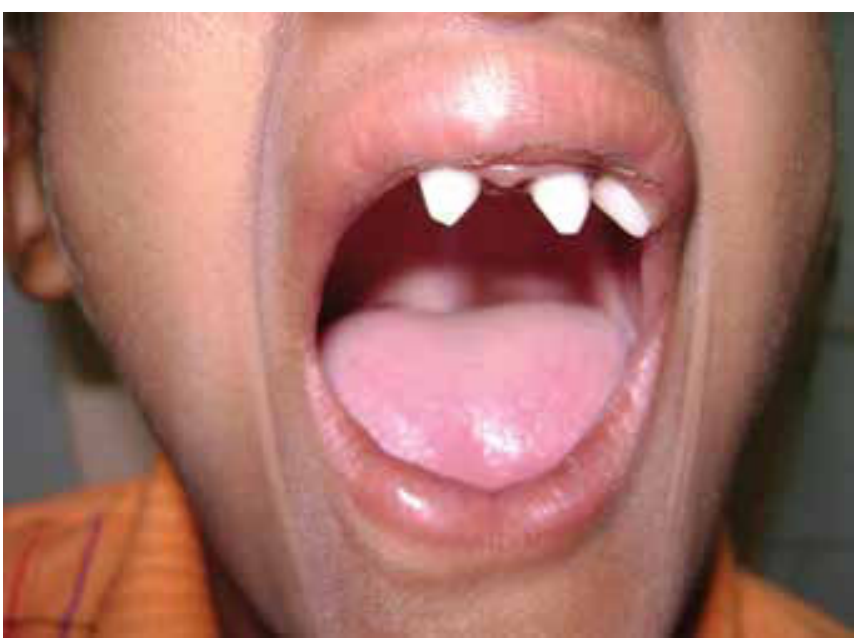

Fig. 2: Conical teeth of the first patient

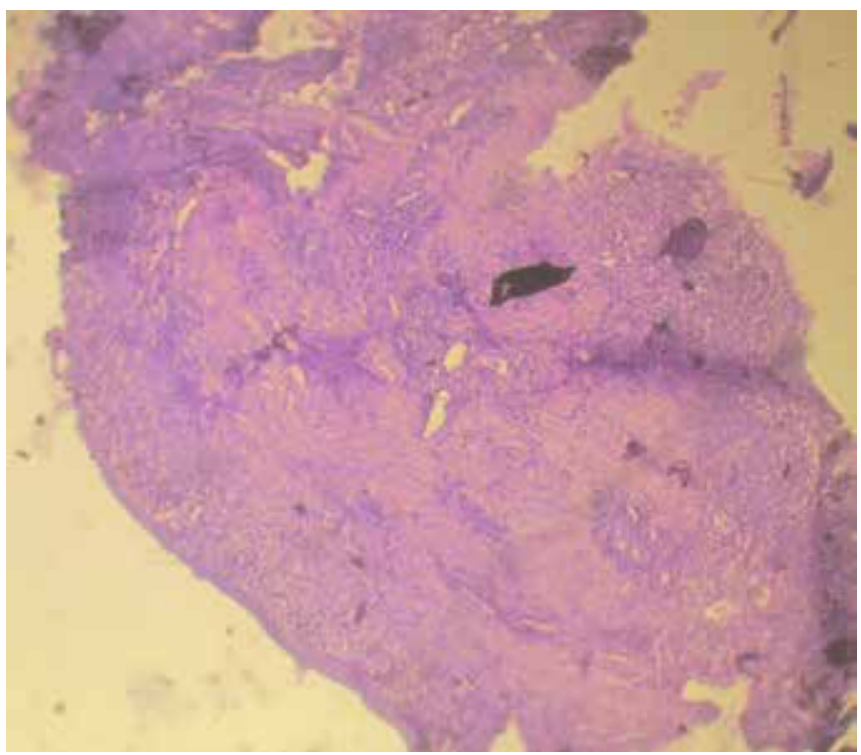

Fig. 4: Nasal mucosal histopathology slide showing absence of mucous glands

\section{DISCUSSION}

Most of the patients of ectodermal dysplasia attend dermatology or dental clinic first. But these rare cases may present with otorhinological manifestations as chief complaint and must be diagnosed by the clinical features and proper history taking. The clinical features are not evident in neonates. Dental, hair and nail anomalies become evident only in early childhood. Other signs and symptoms include xerophthalmia, ${ }^{4}$ xerostomia, ${ }^{5}$ frequent otitis, rhinitis, pharyngitis, ${ }^{6,7}$ growth failure, ${ }^{8}$ etc. Hypoplasia or absence of mucous glands of upper aerodigestive tract is responsible for these manifestations. Till now only few cases have been reported to present with nasal symptoms., ${ }^{90-13}$

For anhidrotic or hypohidrotic ectodermal dysplasia, the inheritance pattern is almost always X-linked recessive. Three genes which are related to ectodysplasin 
protein and its receptor, have been identified in $X$ chromosome at $\mathrm{q} 13$ position. Like all other X-linked recessive disorders only male child will manifest the disease and female carrier will be asymptomatic. But carrier female may sometime show partial manifestation of the disease which can be explained by lionization or inactivation of one of the $X$ chromosomes. ${ }^{14}$ That is why mother of the second child was mildly affected and the child being male suffered from the whole stigmata of the disorder. But the same is not true for the first case because neither his mother nor his brother showed any features suggestive of this rare disorder. This must be a case of autosomal dominant inheritance. The gene for autosomal dominant hypohidrotic ectodermal dysplasia has been mapped to 2q11-q13.

Ectodermal dysplasia is a nonprogressive disorder with good prognosis. Morbidity can be decreased with orthodontic reconstruction; care of nose, ears and oral cavity; maintaining body temperature by lifestyle modification. There are several other forms of the disorder which needs special attention like anhidrotic ectodermal dysplasia with immunodeficiency (EDA-ID) which may give rise to recurrent systemic infection. Hydrotic ectodermal dysplasia patients may suffer from eye changes like cataract, strabismus. An erosive scalp dermatitis may be seen in (ankyloblepharon, ectodermal dysplasia, cleft lip/palate) AEC syndrome whereas ectrodactyly is pathognomonic in (ectodermal dysplasia, ectrodactyly, cleft lip/palate) EEC syndrome. Carrier mother must be counselled about risk in male child. Prenatal diagnosis is possible by fetal skin biopsy or by linkage analysis.

\section{CONCLUSION}

Ectodermal dysplasia is a rare entity which can first present to the ENT clinic with atrophic rhinitis, nasal myiasis or recurrent ear infection. Proper history taking, general examination and family history are the cornerstones of diagnosis. Otorhinolaryngologists play vital role in the health care team managing such patients.

\section{REFERENCES}

1. Thurnam J. Two cases in which the skin, hair and teeth were very imperfectly developed. Proc RM Chir Soc 1848;31:71-82.

2. Weech AA. Hereditary ectodermal dysplasia (congenital ectodermal defect). Am J Dis Child 1929;37:766-790.

3. Stevenson AC, Kerr CB on the distribution of frequencies of mutation to genes determining harmful traits in man. Mulat Res 1967;4:339-352.

4. Kaercher T. Ocular symptoms and signs in patients with ectodermal dysplasia syndromes. Graefes Arch Clin Exp Ophthalmol 2004 Jun;242(6):495-500.

5. Nordgarden H, Storhaug K, Lyngstadaas SP, Jensen JL. Salivary gland function in persons with ectodermal dysplasias. Eur J Oral Sci 2003 Oct;111(5):371-376.

6. Daniel E, McCurdy EA, Shashi V, McGuirt WF Jr. Ectodermal dysplasia: otolaryngologic manifestations and management. Laryngoscope 2002 Jun;112(6):962-967.

7. Mehta U, Brunworth J, Lewis RA, Sindwani R. Rhinologic manifestations of ectodermal dysplasia. Am J Rhinol 2007 Jan-Feb;21(1):55-58.

8. Motil KJ, Fete TJ, Fraley JK, et al. Growth characteristics of children with ectodermal dysplasia syndromes. Pediatrics 2005 Aug;116(2):e229-234.

9. Sachidananda R, Nagadi A, Dass AA, Parveen Kmr BY. Anhidrotic ectodermal dysplasia presenting as atrophic rhinitis. J Laryngol Otol 2004 Jul;118(7):556-557.

10. Wiesmiller K, Keck T, Lindermann J. Atrophic rhinitis in a patient $\mathrm{w}$ anhidrotic ectodermal dysplasia. Rhinology 2005 Sep;43(3):233-235.

11. Dasgupta S, Joshi VS, Murkey NSN, Avad A, Mohanty S. Hypohydrotic (anhydrotic ectodermal dysplasia-a rare cause of childhood atrophic rhinitis. Ind J Otolaryngol Head Neck Surg 2006 Apr;58(2):202-204.

12. Madana J, et al. Hypohidrotic ectodermal dysplasia with atrophic rhinitis and nasal myiasis. Int J Pediatr Otorhinolaryngol 2009;73:1467-1469.

13. Barman D, Mandal S, Nandi S, Banerjee P, Rashid MA. Anhidrotic ectodermal dysplasia presenting as atrophic rhinitis. J Ind Med Assoc 2011 Nov;109(11):836-837.

14. Pediatric Dermatology: Ectodermal Dysplasia. Edited by Laurence A, Schachner and Ronald C. Hansen. 2nd ed. Churchill Livingstone, New York, 1995. p. 361-363. 